\title{
A INFÂNCIA NOS ALMANAQUES: NACIONALISMO, SAÚDE E EDUCAÇÃO (1920-1940)'
}

\section{Moysés Kuhlmann Jr.* Maria das Graças Sandi Magalhães**}

RESUMO: Os almanaques de farmácia foram veículos de difusão não só de medicamentos, mas também de ideias relacionadas com o projeto de modernização da sociedade brasileira. No período entre 1920 a 1940, eles se dedicaram a vários temos vinculados à infância. Associava-se o progresso a uma infância bem-cuidada e disciplinada. As amas de leite e o tipo de amamentação foram objetos de obstinados debates. Além disso, nota-se a preocupação com os aspectos educacionais em atividades como jogos e passatempos, assim como em artigos e editoriais sobre campanhas de alfabetização, a manutenção de escolas e a publicação de materiais didáticos, como abecedários e tabuadas. A mulher é interlocutora privilegiada, tanto em relação aos cuidados e indicações de medicamentos e alimentos quanto nas atividades educativas propostas para as crianças. Cuidar e educar a criança simbolizava a introdução de padrões modernizadores no Brasil.

Palavras-chave: Infância; Almanaques de Farmácia; Nacionalismo.

\section{CHILDHOOD IN ALMANACS: NATIONALISM, HEALTH AND EDUCATION (1920-1940)}

ABSTRACT: The pharmacy almanacs were a source of diffusion not only for medicines but also for ideas related with a project for the modernization of the Brazilian society. In the period 1920-1940 such publications dealt with several topics regarding childhood. Progress was associated with a well-cared and disciplined childhood. Wet-nurses and the type of breastfeeding were the subject of stubborn debates. Besides, it was also common the concern with educational issues in activities like games and pastimes, as well as in articles and texts about literacy campaigns, school maintenance and the publication of didactic materials, alphabets and multiplication tables. The woman is a privileged addressee, both on issues related with medicine and food care, and also on educative activities aimed at children. To care for and to educate a child symbolized the introduction of patterns that modernized many aspects of the Brazilian society.

Keywords: Childhood; Pharmacy Almanacs; Nationalism.

* Docente da Universidade São Francisco (USF); Pesquisador da Fundação Carlos Chagas (FCC); Bolsista de produtividade em pesquisa do Conselho de Desenvolvimento Nacional de Desenvolvimento Científico e Tecnológico (CNPq), nível 2. E-mail: mkuhlmann@pq.cnpq.br

** Doutoranda no Programa de Pós-Graduação da Faculdade de Educação da Universidade Estadual de Campinas (UNICAMP); Professora da Escola Estadual Professora Ayr Picanço B. de Almeida, em São José dos Campos. 
Diversos laboratórios farmacêuticos nacionais e estrangeiros promoveram seus produtos, de forma contínua, ao longo do século XX, por meio da publicação de almanaques, com tiragens que atingiam o milhão de exemplares, com distribuição gratuita nas farmácias em todo o território brasileiro. $\mathrm{O}$ almanaque de farmácia não se restringia somente aos anúncios de remédios, cumprindo outros papéis, como calendário agrícola, religioso e cívico, como veículo de educação sanitária, substituto do médico inacessível, como livro de atividades e de leitura para adultos e crianças.

Contando com colaboradores e ilustradores de renome e tiragem bem acima da média das obras literárias, com grande alcance popular, os almanaques não estão presentes nas prateleiras das bibliotecas. $\mathrm{Na}$ década de 1990, algumas pesquisas utilizaram coleções particulares ou dos poucos laboratórios que conservam algum acervo dos almanaques editados (CASA NOVA, 1996; PARK, 1999). A maioria dos almanaques pesquisados para esse trabalho também pertence a acervo particular. ${ }^{2}$

Foram consultados 155 exemplares, de 45 empresas, 152 deles editados entre 1911 e 1953, por farmácias, laboratórios farmacêuticos brasileiros (36 empresas), filiais e representantes de laboratórios estrangeiros (9 empresas). Também foram consultadas sete edições do Almanaque Nestlé, que pertence ao setor de alimentos. Entre os laboratórios estrangeiros que editaram almanaques no Brasil, cinco possuíam matriz nos Estados Unidos, dois na França, um na Alemanha e um na Suíça.

$\mathrm{O}$ estudo dos exemplares mostrou que a indústria de medicamentos, tanto a nacional quanto a estrangeira, incorporou e divulgou as ideias relativas ao movimento sanitário do período, vinculadas à questão da nacionalidade e à modernização do país. $\mathrm{O}$ estilo de propaganda com entretenimento, utilidades e generalidades colocava em circulação, para o grande público leitor de diferentes regiões e classes sociais, ideias sobre a raça brasileira, o progresso e a ciência, além de regras de higiene para a população.

A autoridade dada pela ciência servia para a divulgação dos medicamentos e produtos oferecidos pela indústria farmacêutica ou de alimentos e reforçava uma representação do progresso ligado ao desenvolvimento científico e à vida urbana. As regras de higiene e as reformas sanitárias podem ser incluídas nesse processo de normatização da sociedade moderna, que tinha na educação da infância um de seus alvos. 
A disciplina em relação aos cuidados com o corpo pode ser estendida à infância nos almanaques estudados, nos quais a imagem da criança saudável quase sempre era associada ao futuro e ao progresso do país, como se expressa no Almanaque Nestlé de 1941 (p. 29), que trazia como símbolo do mês de outubro um monumento à criança, com os dizeres: "Outubro é o mês das comemorações da criança. Govêrno e povo sabem que, na criança protegida, repousa o destino da nação brasileira". ${ }^{3}$

\section{Os almanaques, a amamentação, a saúde e os cuidados maternos}

$\mathrm{Na}$ maioria dos almanaques de farmácia que divulgavam produtos infantis e nos manuais pediátricos editados nas primeiras décadas do século XX, há unanimidade em relação à necessidade do aleitamento materno e uma crítica ao uso das amas-de-leite. Os produtos do Laboratório Nutrotherapico, por exemplo, traziam nos rótulos uma lista de conselhos às mães. Entre eles, a indicação de que "a criança até o $4^{\circ}$ mez deve tomar sómente leite, de preferencia o materno, e ser pesada todos os mezes, até aos 2 annos de idade" (Almanack do Laboratório Nutrotherapico, 1926, p. 21).

Com o aumento da industrialização e o ingresso das mulheres no mercado de trabalho, o que se percebe é a intensificação da propaganda da alimentação artificial. Na década de 1920, a indústria de alimentos passa a oferecer fórmulas lácteas para a alimentação das crianças e a produção de leite em pó ganha um crescente mercado internacional (MARQUES, 2000, p. 48).

Nos almanaques de farmácia brasileiros, na década de 1920, podiam-se encontrar anúncios de alimentos infantis, principalmente leites e farinhas, como a Infantina Granado (farinha lactea malto-phosphatada), que era anunciada, em 1926, no exemplar de O Pharol da Medicina, como substituta do leite materno, "sempre que fosse necessário recorrer à alimentação artificial” (Fig.1). O almanaque do mesmo ano do Laboratório Nutrotherapico divulgava o Creme Infantil e a Nutramina, produzidos até a década de 1940. O anúncio da também nacional farinha nutritiva Wittrock podia ser encontrado nas últimas páginas do Guia das Mães, de 1947.

Em concorrência com os laboratórios brasileiros, os alimentos produzidos pelas empresas estrangeiras acabaram se sobrepondo aos 
nacionais, num processo que teve início ainda no final do século XIX, com a entrada da farinha láctea Nestlé no Brasil. A Nestlé introduziu, posteriormente, o leite condensado Milkmaid (Moşa), o leite em pó integral Molico, antecessor do leite Ninho, e o Nestogeno ${ }^{4}$. A propaganda do Almanaque Nestlé (1940, p. 13) oferecia o leite industrializado desde os primeiros dias de vida da criança: "Lactogeno é um leite em pó preparado pela Nestlé, de composição semelhante à do leite materno, e especialmente indicado para a alimentação dos bebês, desde os primeiros dias. Leite em Pó LACTOGENO faz crianças fortes e alegres".

Outras empresas estrangeiras também introduziram no país opções de leites industrializados, como o leite Dryco, da norte-americana The Borden, e os produtos da Mead Johnson, também dos EUA, que anunciava uma série de alimentos infantis, como o Nutramigem ou o Leite lato ácido meio desnatado Mead, na revista Pediatria Prática (set./out. 1949).

Os argumentos a favor da alimentação artificial vão desde os ligados à eugenia, que difundia a ideia de transmissão das limitações de uma raça miscigenada, via amamentação, até o apelo aos valores cristãos. Para viabilizar o uso do produto industrializado, a mamadeira tornava-se indispensável. Não por acaso é que se pode encontrar no $A B C$ Illustrado, "offerecido gratuitamente pelos proprietários da Farinha Lactea Nestlé" (1928), o B de "biberon, empregado para dar de comer ás creanças a farinha lactea Nestlé" (Fig. 2). A denominação mamadeira ainda não era a norma, daí o uso da expressão em francês.

O aumento da oferta dos leites industrializados no Brasil, a partir da década de 1930, produziu mudanças nos discursos médicos relacionados à amamentação. Segundo Almeida (1999, p. 39), a corporação médica, aos poucos, deixou de condenar o desmame para, subliminarmente, estimular a alimentação artificial com a mamadeira.

As noções de cuidado e tratamento para as crianças estão presentes nos almanaques pesquisados em tabelas de pesos e medidas, na descrição dos períodos de dentição, além da recomendação dos tradicionais tônicos fortificantes e depuradores do sangue, dos vermífugos, laxantes, cremes e farinhas infantis. Além dos cuidados higiênicos, o uso de remédios modernos, diferentes das mezinhas populares, fabricados por laboratórios conceituados, também fazia parte do novo ideário de país civilizado que se queria atingir. 
Em relação ao medicamento infantil, os depoimentos sobre o uso de remédios nas clínicas pediátricas e instituições indicam uso experimental, pelo menos até a década de 1930. É o que transparece na surpreendente recomendação de médicos conceituados a determinados remédios, muitas vezes usando o nome de instituições, como podemos ver na carta de Moncorvo Filho ao Laboratório Nutrotherapico, escrita em novembro de 1921:

Acquiescendo ao pedido de VV.SS. para ensaiar em doentinhos soccorridos no Instituto de Protecção á Infancia do Rio de Janeiro o producto denominado LAXO-PURGATIVO INFANTIL, por VV.SS. enviado, cumpro o dever de communicar-lhes haver o alludido preparado sido empregado com o melhor resultado, nos casos em que houve indicação, parecendo tratar-se de um bom medicamento (Almanack do Laboratorio Nutrotherapico, 1926, p. 11).

O Laboratório Nutrotherapico utilizou depoimentos de médicos ligados a hospitais, clínicas pediátricas e instituições de assistência à infância. Chegou inclusive a utilizar comunicações acadêmicas na propaganda de seus medicamentos, talvez como forma de convencimento dos próprios médicos, como se pode verificar no Guia de Produtos do Laboratório Nutrotherapico, de 1925:

AMINA-ZIN: O estudo deste preparado foi inspirado na brilhante communicação feita à Academia de Medicina pelo illustre pediatra Dr. Fernando (sic) Figueira, em 20.10.1921, sobre um preparado vitaminoso de succo de cenoura, que lhe enviou o Prof. Aron, de Bréslau, com o qual obteve notaveis augmentos de peso e cura definitiva em crianças.

Somando-se à importância atribuída à amamentação e à saúde, os almanaques colocaram em relevo outro aspecto da maternidade e dos discursos sobre os fundamentos das nações modernas: a educação. Os editores buscavam orientar as mulheres leitoras sobre as atividades domésticas, os cuidados médicos ou como se comportar em relação aos homens, como a seção do Almanack do Biotonico intitulada: O que interessa às mulheres (1929, p. 9). Havia também artigos e seções que propunham atividades para as crianças. Era a mulher a intermediária para disciplinar e socializar as crianças, tanto com a adoção de horários corretos para a alimentação ou do aprendizado das tarefas domésticas, quanto em relação à educação pré-escolar e primária. 
Para os editores do Almanaque Nestlé, a missão cívica destinada à mulher resumia-se na garantia da felicidade do lar, na organização dos afazeres domésticos e, sobretudo, na responsabilidade pelos cuidados e pela educação dos filhos. Ideal explícito na poesia de Belmiro Braga, na edição de 1940 (p. 6):

Para as mães, o mundo imenso

Não vai dois palmos além

Do filho nos braços suspenso

Que é neste mundo o seu bem.

A regularização dos horários da criança, a proibição dos doces e o controle rígido do horário das refeições, a indicação do banho "quasi frio”, a pesagem obrigatória todos os meses até os dois anos são conselhos que surgem nas páginas dos almanaques. Revela-se a intenção de educar as mães e criar novos hábitos de disciplina e consumo em direção à nação que se idealizava. Os dizeres no selo da marca registrada do Almanack Nutrotherapico são emblemáticos dessa relação entre a ideia de disciplina e os cuidados com a criança:

A saúde e a robustez constituem um começo de fortuna.

A balança e o relógio são a bússola da saúde da criança.

Cuide-se sem demora e fortaleça seu filho.

Neles podemos observar duas ideias interligadas: a importância da saúde, vinculada à imagem da robustez e da disciplina, representada pela balança e o relógio, como meio para se atingir a fortuna, associada à ideia de progresso. Além disso, também o adulto teria a responsabilidade de cuidar-se no presente, para evitar as doenças endêmicas que causariam a impureza do sangue, e garantir o futuro: a criança.

\section{Os almanaques, a escola e o nacionalismo}

A um pedido de favores especiais para a remessa de almanaques às cidades do interior do Brasil, um dos últimos Ministros da Viação deu despacho favorável, acrescentando que o ALMANAQUE no BRASIL bem merecia a gratidão dos poderes públicos, pois era 'O Livro do Pobre', encontrado em todos os lares, por mais humildes, por mais afastados que sejam. Vigoroso 
auxiliar do Govêrno na Campanha de Alfabetização do povo brasileiro, ALMANAQUE BRASIL continua sua marcha vitoriosa, assinalando este ano seu terceiro milhão de exemplares impressos e distribuidos em todo o território nacional. (...)

J. Muniz \& Cia. Editores (Almanaque Brasil, 1941, p. 1)

O movimento que levou Getúlio Vargas à presidência da República incorporou parte das ideias que contribuíram para a consolidação de um Estado centralizado no Brasil. Esse processo de centralização política se desenvolveu ao longo das décadas de 1930 e 1940 e teve como uma de suas características a ênfase maior no papel das instituições escolares, sinalizando um segundo momento em relação às discussões que envolveram saúde e educação.

A capa de 1949 do Almanaque do Licôr de Cacau Xavier destaca o papel da escola como elemento de valorização da nacionalidade. Ao fundo da ilustração há um mapa do Brasil e sobre ele caminham uma menina e um menino com uniforme e material escolar. A frase em destaque ressalta a importância da escola para o país: "É com os pés das crianças que a Pátria caminha”.

Nos almanaques, as imagens de crianças escolarizadas tornaramse mais comuns a partir da década de 1930. Da divulgação de hábitos higiênicos e dos cuidados com as crianças, passou-se progressivamente também a fomentar campanhas de alfabetização e a associar a infância com a instituição escolar.

Um aspecto que chamou a atenção foi o número reduzido de menções a crianças escolarizadas nas edições estudadas na década de 1920. No caso do Almanack do Biotonico, entre 1926 e 1949 (exceto 1928, 1933 e 1943), apenas no exemplar de 1935 menciona-se a escola, mas não há referência direta ao uso de seus produtos com os escolares. Nas décadas seguintes, o fortificante Biotonico Fontoura foi vinculado à melhoria do rendimento escolar, em especial na campanha promocional que usava o bê-a-bá (PARK, 2003). Essa tendência fica marcada na edição de 1950, quando o Almanaque do Biotonico (p. 16-17) trouxe em suas páginas centrais o anúncio "Os brasileiros de amanhã", com a ilustração de um menino em idade escolar escrevendo o nome do fortificante indicado, com livros a seu lado. Outro anúncio do fortificante intitulado "Seu filho teve notas más?” (p. 10) referia-se ao desempenho escolar. 
Em outros almanaques, a partir da década de 1930 aparecem algumas menções às crianças que frequentavam a escola, em geral relacionando o fracasso escolar a problemas de saúde. Foram onze referências diretas, entre os anos de 1931 a 1953. O Almanaque Bayer de 1931 destacava a importância das escolas, na seção "Conheçamos o nosso paiz": "A instrucção publica primaria é dada em 22.664 escolas; a secundaria no COLLEGIO PEDRO II e em 25 gymnasios estaduaes e 30 institutos particulares áquelle equiparados" (p. 26).

Havia anúncios que representavam situações em que as crianças apareciam na sala de aula, indo para a escola ou saindo dela. Os desenhos feitos por Kohout no Almanach d'A Saude da Mulher, de 1932, ilustram a propaganda do xarope Bromil, mostrando o interior da sala de aula e a saída de uma escola primária. A primeira figura mostra uma classe mista e, embora a professora se apresente como o centro da imagem, as crianças também se destacam como elemento ativo da propaganda.

Em relação à imagem dos professores, podemos encontrar dois exemplos que ainda identificavam o magistério como atividade masculina. Em 1932, o Almanak Xarope S. João divulgava o fortificante Vigonal com o exemplo do professor que recomendava o produto aos alunos sem ânimo para o estudo. O Almanaque do Biotonico de 1935 trazia a história em quadrinhos "O papagaio da Botica", em que a personagem principal, Finoca, é apresentada como a "peior alumna da classe". Nesse caso, o que chama a atenção é a figura do professor portando uma palmatória.

Resolver os problemas que provocavam o fracasso escolar tornou-se uma das atribuições de diversos medicamentos anunciados nos almanaques. Podemos encontrar um desses exemplos no Almanaque Guaraína, de 1940. O anúncio era precedido de ilustração, mostrando um aluno com orelhas de burro, ridicularizado pelos colegas (p. 13):

\footnotetext{
A Casa do Suplício

Veja a tortura moral a que seu filho é submetido na escola por ser o último da classe. Entretanto, é uma criança que merecia melhor destino, pois se tem o cérebro fraco, o seu coração e sensibilidade são perfeitos e ele chora lágrimas de sangue por não poder acompanhar seus companheiros nos vivos progressos que fazem.

O atraso de seu filho nos estudos vem apenas de fraqueza geral que êle sente.

Dê-lhe "Calciovitamina". Faça do seu filho uma criança sadia, para a qual a escola não mais constitua como hoje, uma casa de suplício.
} 
Da mesma maneira, a história de Juquinha, intitulada “ $O$ Último da Classe”, na edição de 1935 do Almanak Cabeça do Leão (p. 10), recomendava em seu final a Salsaparrilha do Dr. Ayer, para transformar o menino, considerado a "vergonha da família, em entusiasmado no estudo e decidido a conquistar, ponto a ponto, a melhor colocação na lista dos estudantes seus colegas".

A escola passou a ser representada como um aspecto importante na vida da criança, a ponto de tornar o mau rendimento uma "tortura" para ela e também para a família. Indício de que, em relação à infância, o discurso sobre o progresso incorporou a instituição escolar de forma ainda mais clara como um de seus elementos, destacando-a da definição mais ampla de educação, relacionada em geral nos almanaques do período anterior aos hábitos higiênicos e aos cuidados com a saúde.

Outro tipo de referência, relacionada a ações concretas, aparece na década de 1940. Ao mudar o nome do almanaque editado desde a década de 1920, os Laboratórios Raul Leite faziam um balanço dos "quasi quatro lustros" de sua existência. Creditavam o fato de ocuparem o posto de "maiores da América do Sul" não só ao seu "escopo meramente comercial, mas sim ao mais alto propósito patriótico e humanitário". Entre suas "iniciativas beneficiadoras da coletividade" incluía-se a ajuda a hospitais e a colaboração em campanhas sanitárias, a "manutenção de escolas em todos os Estados do Brasil" (Almanaque Guaraina, 1940, p. 1). O nacionalismo já aparecia, em 1939, no selo divulgado na contracapa do almanaque, que imitava a bandeira brasileira. O editorial do ano de 1941, comemorando os 20 anos da empresa, especifica que mantinha "escolas de alfabetização em todo o Brasil". Tratava-se de uma ação, na opinião dos editores, que reforçava o patriotismo mencionado no ano anterior: "Firmados em toda uma seqüência de realizações proveitosas para a nacionalidade, os Laboratórios Raul Leite muito se comprazem em desejar a todos um feliz e próspero 1941” (p. 1).

Os almanaques também foram instrumentos de popularização das ideias que se voltavam à educação das crianças menores, à puericultura e à eugenia, concretizadas nos jardins de infância e creches. No Almanaque Nestlé de 1940, considerava-se que "o emprêgo dos produtos Nestlé nos lactários, créches e hospitais é um atestado da preferência que lhes dispensa a classe médica brasileira" (p. 5). No artigo intitulado "O crime dos Paes", que promovia a Salsaparrilha do Dr. Ayer, na edição de 1934 do 
Almanak Cabeça do Leão, há uma referência à ação governamental em relação ao emprego de creches como um dos elementos da "regeneração da raça":

Crear uma geração futura, forte e sadia, preparando mais altos destinos para a patria, é hoje preoccupação de todos os povos cultos.

Para esse fim o Estado interessa-se com a natalidade, prestando assistencia ás mães, creando "créches", solarios, campos de gymnastica, etc., protege os desportos de todo o genero, em summa, tudo faz para que a geração por vir seja dotada physicamente de condições perfeitas de saude, vigor e efficiencia. (p. 10)

\section{Os almanaques e as atividades didáticas}

Os almanaques de farmácia excederam sua função de propaganda, compondo um conjunto de materiais que divulgavam um discurso civilizador. Ao objetivo de ensinar os cuidados que garantiriam crianças saudáveis e trabalhadores preparados e disciplinados, aliam-se outras atividades que também podem ser relacionadas à educação. Mediante passatempos ou orientações às mães, os almanaques traziam ao leitor conhecimentos próximos ao universo escolar. O texto da página que abre o $A B C$ de João e Maria, editado pela Nestlé em 1940, é emblemático da interligação entre esses dois aspectos: "A Instrução e a Saúde são as bases dum grande povo. Uma criança doente não apprende, ou apprende com difficuldade. O Médico e o Professor devem andar sempre juntos. $\mathrm{Na}$ sua acção conjuncta repousa o destino do Brasil".

A contracapa do Almanack do Biotonico de 1926 simboliza a concepção de educação relacionada a hábitos e valores veiculada nos almanaques da década de 1920. A ilustração mostra duas meninas à mesa, uma delas um pouco mais velha que a outra, servindo à menor uma colher do Biotonico. A imagem dialoga com a criança, que se identifica na gravura. Promove o exemplo de organização e de disciplina, incentivando o cuidado com a saúde desde a infância.

Mas a década seguinte colocaria em pauta novas necessidades: trabalhadores saudáveis, disciplinados e capazes de votar. Tornou-se necessário alfabetizar os brasileiros. E, mais uma vez, os almanaques se adequaram ao seu tempo, incluindo atividades ligadas à cultura escolar em 
seu repertório. Em 1932, o Almanaque Bayer reproduz essa ideia ao publicar o artigo "Dever de cada um”, de autoria do médico Mário Pinto Serva, que além de conclamar os brasileiros que sabiam ler a se tornarem alfabetizadores, relacionava essa atividade com o futuro do país: "Um povo só pode ser grande pela educação diffundida a todos e aperfeiçoada em cada indivíduo. (...) O futuro do Brasil está no problema da educação do povo" (p. 17).

$\mathrm{Na}$ mesma linha, mas com o público infantil como alvo, o editorial do Almanaque Nestlé de 1940 considerava que a empresa "contribue para o bem da criança brasileira por todos os meios ao seu alcance", o que se dava em três níveis: com os médicos, com os educadores e com as autoridades. Em relação aos educadores, indicava a "distribuição de milhares de ABC, desenhos para colorir, e outro material educativo". O editorial finalizava afirmando: "É dentro dessa rota que a Nestlé tem sempre caminhado e sempre caminhará, procurando atingir, com seu esfôrço, o sagrado objetivo de melhorar a nossa raça” (p. 1).

O editorial do Almanaque Nestlé de 1941 foi ilustrado por fotografias de crianças em instituições consumindo os produtos da empresa ${ }^{5}$. Nesse ano, além da distribuição gratuita de merendas nas escolas, doação de seus produtos para hospitais, creches e ambulatórios, os editores do Almanaque Nestlé detalhavam os títulos "de caráter educacional e instrutivo", oferecidos gratuitamente aos interessados: "ABC de João e Maria" e "Tabuada de João e Maria", de Marques Rebêlo e Santa Rosa; "Ginástica Infantil", do Dr. Adauto de Rezende; "Alguns Conselhos Psicológicos aos Pais", do Dr. Leme Lopes; "Pequeno Dicionário de Nomes de Pessoas", de Rômulo de Castro; "Nosso Amigo o Sol" (Helioterapia), do Dr. Cesar Nogueira da Gama (Almanaque Nestlé, 1941, p. 1).

Quanto ao livro Ginástica Infantil, podemos detectar um indício da discussão promovida pelos médicos e educadores sanitários sobre a necessidade dos exercícios físicos na infância. No Almanack Xavier, de 1932, na seção "Alguns conselhos úteis para os que soffrem", destaca-se a frase: "A gymnastica é a medicina do futuro" (p. 23). No Almanaque Silva Araujo de 1934, o artigo "A educação física no Brasil" defendia a criação de escolas que formassem professores para o ensino da educação física às crianças.

Em relação ao $A B C$ e à Tabuada de João e Maria, há uma intenção clara de estimular o aprendizado doméstico. No Almanaque Nestlé de 1939 
(p. 6), o artigo "A Nestlé e a educação infantil" deixava claro o objetivo desse tipo de publicação:

A educação é a base da hygiene. E da hygiene depende a saúde. Não satisfeita em alimentar as crianças, desde os primeiros dias do nascimento, a Nestlé procura instruil-as distribuindo enorme edição de "ABC". Desta forma irão as crianças brasileiras, de uma maneira interessante e pedagogicamente bem elaborada, identificando-se, pouco a pouco, com os mysterios do alfabeto.

A educação higiênica caminhava em conjunto com os aspectos da escolarização em diversos almanaques. Há alguns exemplos que conjugavam higiene e alfabetização em materiais de divulgação, como o caso da Cartilha de Higiene - Alfabeto da Saúde, de autoria de Renato Kehl, com ilustrações de F. Acquarone (193?). Mas, no caso da Nestlé, o investimento pedagógico estava na promoção dos alfabetos e tabuadas, instrumentos que pretendiam popularizar a leitura e o domínio dos cálculos matemáticos.

O primeiro material educativo distribuído pela Nestlé data de 1928, o ABC Illustrado da Farinha Láctea, de 1928, combinava em suas páginas a promoção de produtos da empresa com as letras do alfabeto, com ilustrações provavelmente europeias. A apresentação alertava as crianças de que era tempo de deixar as brincadeiras e encarar "cousas mais sérias", definindo a publicação como o "primeiro alimento de vossa intelligência" (ABC Illustrado, 1928, p. 2). Na década seguinte, a Nestlé produziu um material com "sentimento brasileiro", com autor e ilustrador reconhecidos, mas que também promovia seus produtos. A apresentação do abecedário em 1939 mencionava o apoio de pedagogos:

O ‘ABC de João e Maria’ editado pela Companhia Nestlé, mereceu o applauso das classes cultas, do mundo official e todos os technicos em pedagogia. Feito com arte e intelligência, é um brinde de utilidade sempre opportuna. (Almanaque Nestlé, 1939, p. 6)

A principal mudança que pode ser notada em relação ao $A B C$ Illustrado de 1928 está no uso de frases ligadas ao cotidiano das crianças, que são as personagens principais do livro. $\mathrm{O}$ uso de frases com palavras relacionadas à ilustração associado à apresentação de outras palavras não identificadas na imagem representa uma mudança em relação ao abecedário anterior. Nesse caso, não há o uso do método silábico. 
O Almanak Xarope São João, embora não contivesse nenhuma seção ou artigo declaradamente infantil, apresentou o "Alphabeto da saúde" na edição de 1927 (p. 6) e, na de 1932, destacava as vogais no anúncio em forma de acróstico (p. 27) de um de seus produtos. O alfabeto da edição de 1927, dirigido aos pais, relacionava as letras com palavras simples e prescrevia procedimentos básicos de higiene, para se ter filhos úteis à Pátria:

Alphabeto da saúde

A- Ando calçado; B- Bebo leite; C- Cômo legumes; D- Durmo Limpo; EEscovo os dentes; F- Faço gymnastica; G- Garfo, colher e copo cada um com o seu; H- Hoje bebo laranjada; I - Isto de saúde é commigo; J- Jógo ao ar livre; K- Kilos de peso só para quem tem saúde; L - Lavo sempre as mãos; M- Mastigo devagar; N- Não obro no chão; O - Ovos e legumes são bons alimentos; P- Penteio sempre os meus cabellos; Q - Quero correr para crescer; R- Roupa limpa sempre uso; S- Sigo bem taes conselhos; T- Tomo banho; U- Uso lenço; V- Vaccina vale ouro; X - Xarope, só o São João; Y Yayá anda e senta em bôa posição; Z- Zero vale quem é porco.

Quando seu filho cumprir esses preceitos pode consideral-o um homem util, para a Familia e para a Patria.

Os almanaques de farmácia podem ser incluídos na lista dos impressos que promoveram um contato com a cultura escolar, mesmo sem, muitas vezes, mencionar a escola de forma direta. Havia diversos passatempos e curiosidades que se aproximavam das atividades escolares, com propostas que se apropriaram de ideias e práticas pedagógicas que circulavam no Brasil nas décadas estudadas.

A maioria dos almanaques mantinha seções com problemas matemáticos e de geometria que desafiavam os leitores, jogos com montagem de figuras, contos e poesias infantis, em meio a artigos gerais. Faziam-se promoções, com brindes para os que decifrassem, por exemplo, as cartas enigmáticas. As seções e artigos interessavam aos adultos, mas também às crianças, que faziam outros usos da publicação, como se pode deduzir de alguns exemplares analisados que trazem ilustrações coloridas pelos leitores.

As seções de passatempos utilizavam atividades ligadas ao ensino da matemática e da física, com problemas lógicos e experiências. A edição de 1930 do Almanak Xarope S. João (p. 12), por exemplo, ensinava aos leitores o conceito de inércia, com a experiência que propunha retirar uma tira de papel sob um copo cheio. Já o Almanach Elixir de Inhame de 
1926 (p. 7) apresentava o problema intitulado "Os nove pontos", envolvendo conceitos de matemática e geometria. A seção "Curiosidades Matemáticas" do Almanaque Nestlé de 1941 (p. 6), além de desafiar os leitores a resolver problemas matemáticos, indicava operações que produziam resultados notáveis. No Almanaque do Biotonico, as experiências com copos, garrafas e outros materiais, que demonstravam conceitos de física, aparecem, em 1934, na seção "Para passar o tempo", e, em 1937, atividades parecidas receberam o título de "Sciencia recreativa".

Havia também assuntos ligados à geografia ou à história, com curiosidades, datas comemorativas com conteúdo cívico e personagens históricos. O Almanaque Nestlé de 1941 ilustrou os meses do ano com monumentos ligados a personagens da história do Brasil, como Tiradentes ou o Marechal Deodoro. Para Vera Casa Nova (1996, p. 133), os exemplos de patriotismo em personagens históricos, como Deodoro, Floriano, Caxias, Bilac, nos almanaques, ligava-se à influência positivista e à sua doutrina da reforma da sociedade e da conduta dos indivíduos.

Outro tipo de atividades propostas nos almanaques pode ser relacionado à educação pré-escolar, como a "página das crianças" do Almanaque Bayer de 1932 (p. 12). Essa seção mantinha o padrão de desafios geométricos e de ilusão de ótica usado nos passatempos destinados a todos os leitores, mas introduzia atividades para as crianças menores, como as instruções para se desenhar um gato utilizando botões. Não foi possível acompanhar a permanência desse tipo de atividade no almanaque em questão, pois não houve acesso a outros exemplares, com exceção da edição de 1950, na qual, embora não houvesse uma seção específica para as crianças, havia uma página dedicada aos "recitativos infantis" (p. 12).

Em 1931, o Almanak Xarope S. João reproduzia a atividade de sombras feitas com as mãos, denominada "sombrinhas chinezas" pelos editores (p. 27). A edição de 1938 do Almanach d'A Saúde da Mulher (p. 27) também propunha a mesma brincadeira. Esse tipo de atividade, na qual, por meio de gestos com as mãos, projetavam-se sombras na parede, havia sido sugerido por Froebel no livro Muther-spied und kose-lieder (Jogos para a mãe e canções carinhosas), de 1844 (KUHLMANN JR., 2004, p. 115).

A edição do laboratório norte-americano Vinhetas Vick, de 1938 (p. 6), trazia a seção "O que as crianças gostam de fazer", com orientações sobre "brinquedos de fácil construcção". Outra edição, sem data, ensinava às mães como organizar uma caixa com materiais destinados a entreter as 
crianças, a "caixa dos brinquedos", que deveria conter caixas de papelão, latas, sacos de papel, botões, envelopes, jornais e revistas, além de papel em branco e crayons. A ideia de se utilizar o jogo e a experimentação como forma de aprendizado aparece nessas atividades, que estimulavam o uso de materiais diversificados. Havia outras atividades, como as instruções que solicitavam ajuda para uma ave apanhar a borboleta e chegar ao ninho, sem cruzar nenhuma linha do labirinto (Almanach d'A Saude da Mulher, 1937, p. 11). No Almanaque do Biotonico de 1934 (p. 5), um texto convidava a criança a colorir os espaços numerados do desenho para descobrir De que foge o ratinho.

Nas edições do Almanaque Nestlé de 1940 e 1941, também se encontram atividades para as crianças envolvendo brincadeiras, com jogos que promoviam os produtos da empresa. Os participantes deveriam montar um dado de papel, conforme o modelo sugerido no almanaque, além de recortar as peças que indicariam a posição de cada jogador no tabuleiro. Em 1940, as páginas centrais do almanaque eram ocupadas pelo tabuleiro do jogo, que, no ano seguinte, em tamanho menor, era apresentado na contracapa do almanaque. Em 1940, a criança iniciaria o jogo saindo de casa, passaria pelo campo e pela fábrica da Nestlé, até chegar à escola, que embora não fosse identificada como tal, tinha a mesa posta para a merenda, ao lado da bandeira hasteada. As imagens do jogo da edição de 1941 destacavam animais africanos e asiáticos, montados por bebês que traziam referências dos países daqueles continentes, embora não houvesse nenhuma criança negra. Os bebês carregavam mamadeiras e diversos tipos de leite em pó produzidos pela empresa.

Em 1953, a edição do mesmo almanaque também trazia um jogo em suas páginas centrais. Era uma estratégia de propaganda dos produtos da empresa, como forma de memorização da marca e dos usos incorporados ao cotidiano - como na merenda escolar - que via o jogo como atividade necessária ao desenvolvimento das crianças.

$\mathrm{O}$ efeito que essas atividades presentes nos almanaques, ou os materiais educacionais oferecidos pelas empresas como brindes, tiveram em relação aos processos autodidatas de aprendizagem da leitura ou para o reforço escolar no ambiente doméstico é um problema de pesquisa a ser mais bem-estudado. Mas é inegável que esse material circulou em grande quantidade pelo país e por várias décadas, o que pode significar um grau de aceitação bastante elevado, relacionado a diversos tipos de motivação. 
A propaganda de medicamentos e alimentos infantis, as curiosidades, as atividades propostas, os textos e anedotas e as imagens relacionadas aos textos, apresentados em linguagem simples, estabeleciam diferentes vias de comunicação com o público leitor. Com relação à infância, a mulher era interlocutora privilegiada, tanto para os cuidados e indicações de medicamentos e alimentos quanto para as atividades educativas propostas às crianças. Cuidar e educar a criança simbolizava a introdução de padrões modernizadores no Brasil.

\section{Imagens}

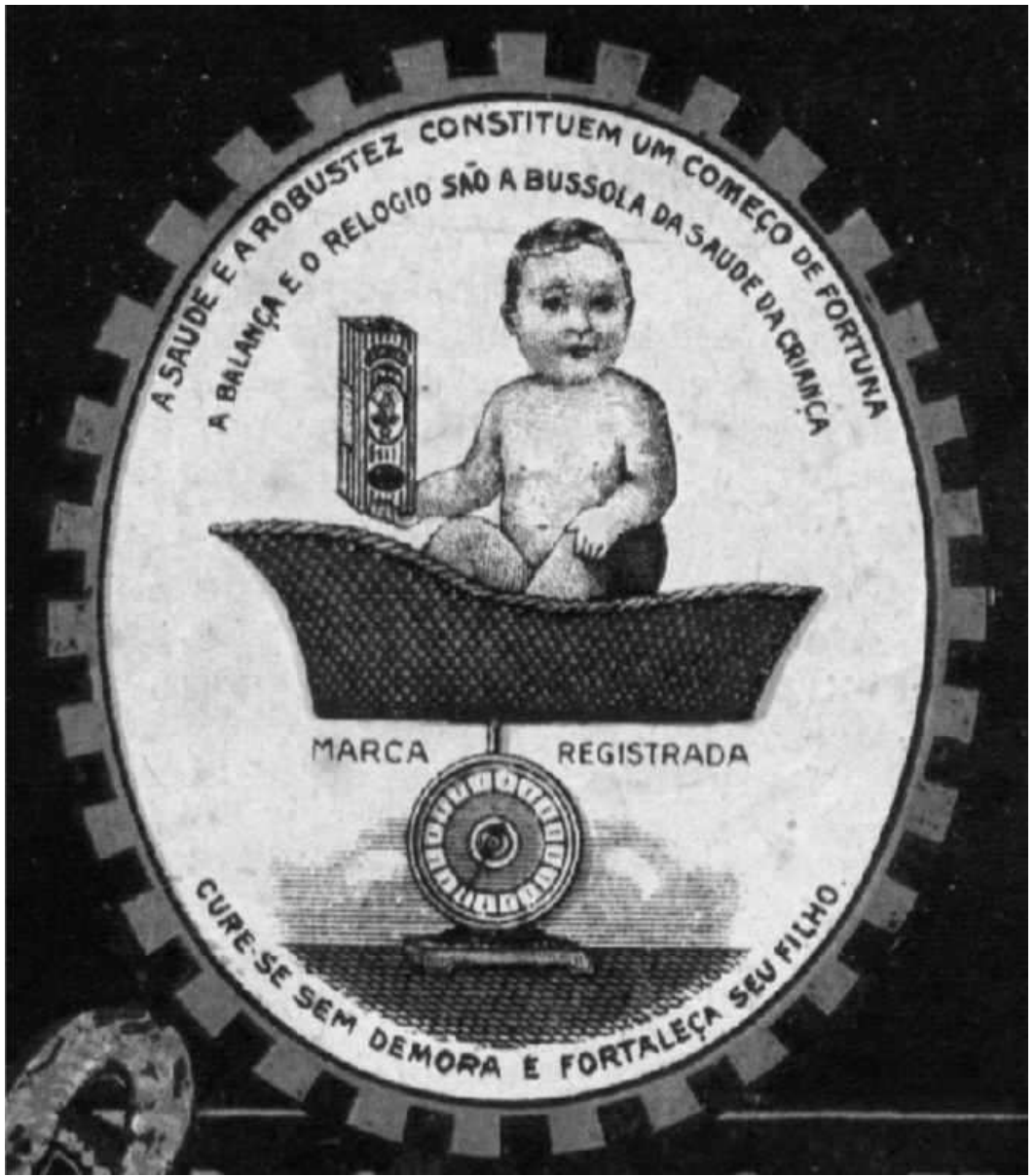




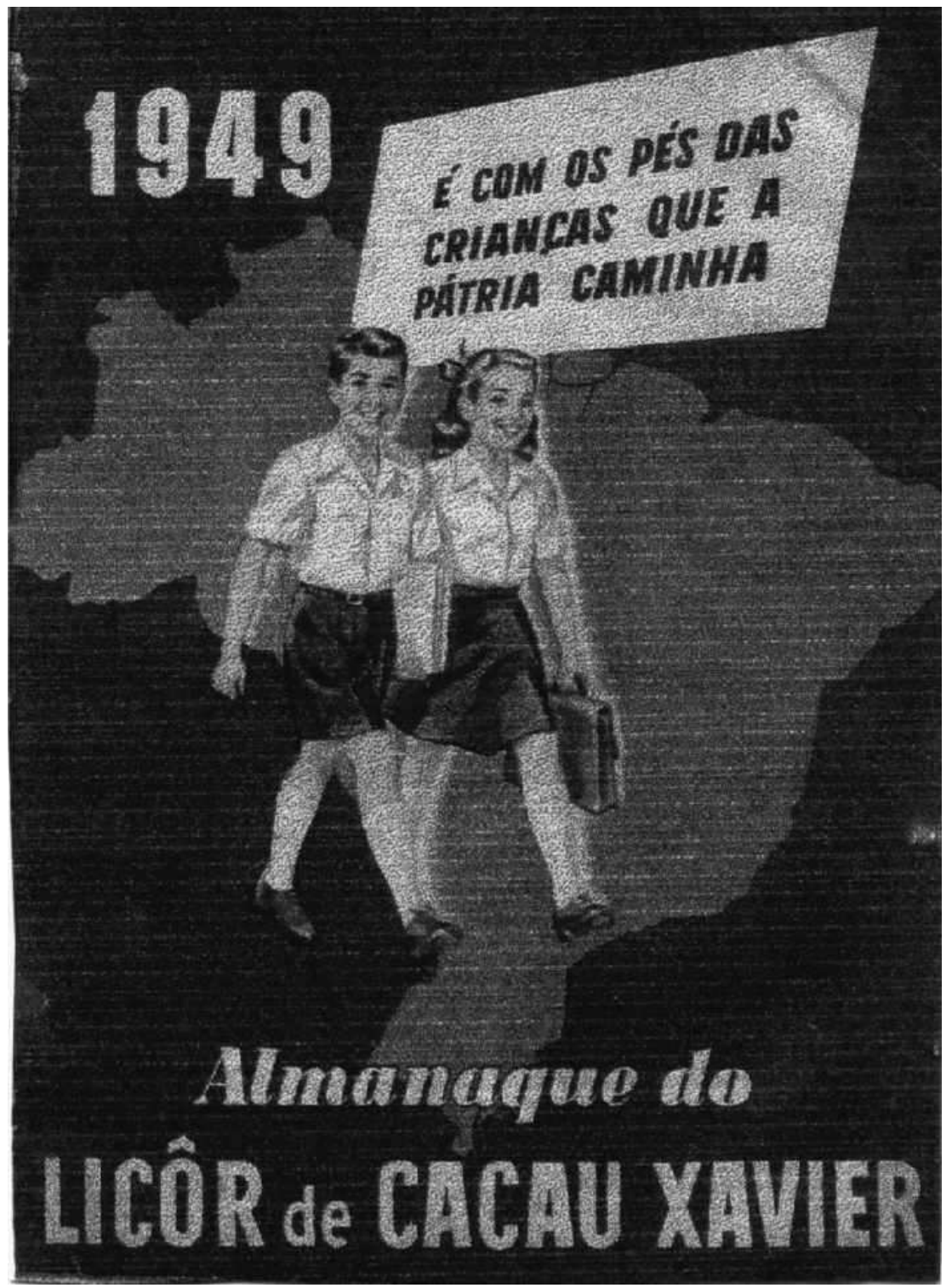




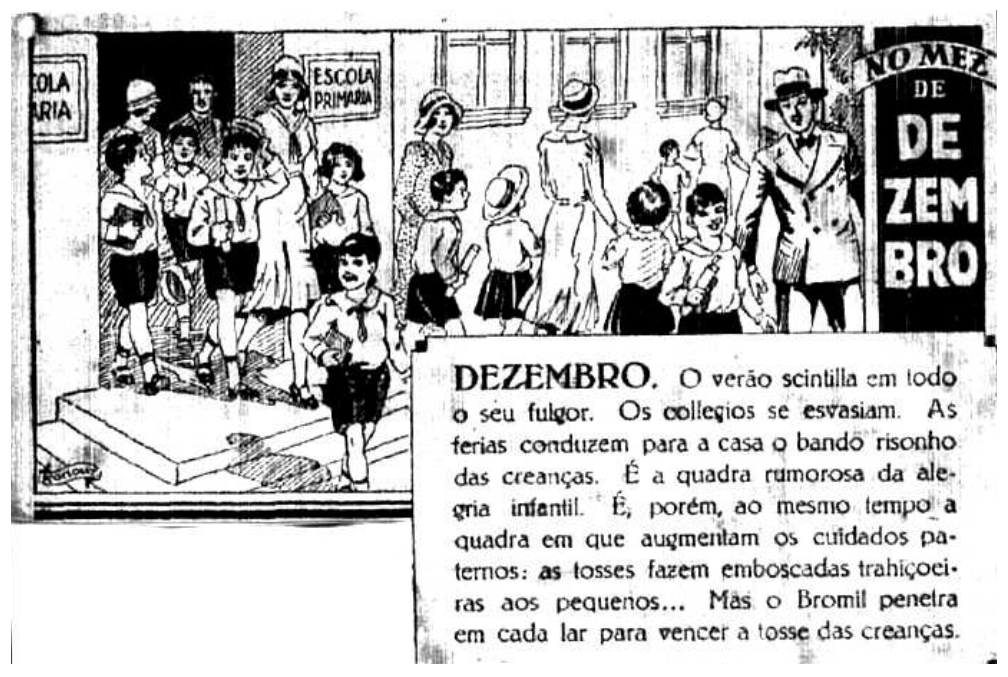

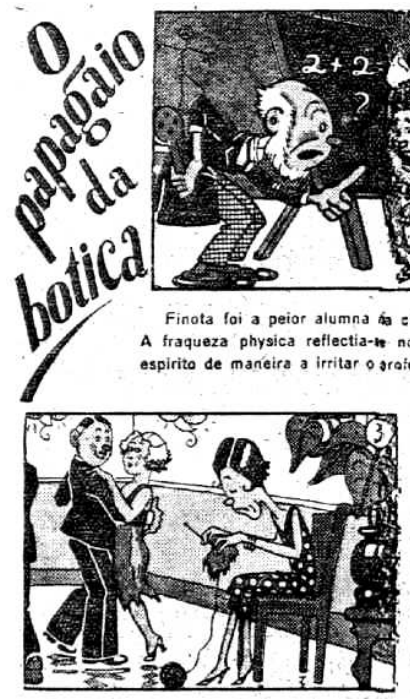

Nos salóes tinha sempre de ficar a um canb Ninguem se lembrava de tiral-a para uma cos tradanca. Assim viveu até o dia em que

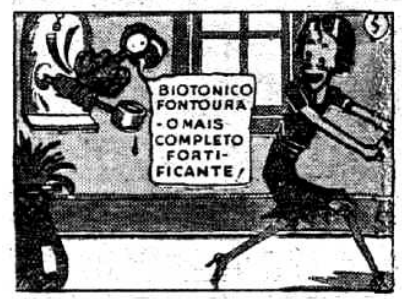

... ouvira dizer na botica, deu à pobre moça una idea. "O BIOTONICO, quem sabe? E a uitima, cousa que resta experimentar.

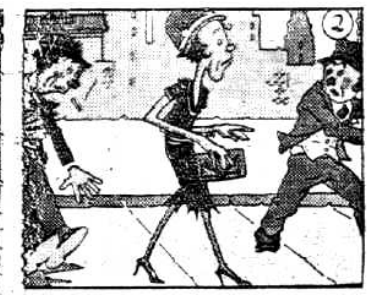

Cresceu anemica, pallida, feia. Quando sahia a rua todos a evitavam. Seu aspecto de "tia" afugentava os homens.

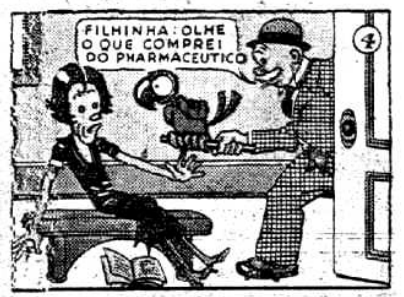

The deram de presente um papagaio muito fraclor, que tinha pertencido a uma botica. Esse pauragaio a salvou. De tanto repetir o que constastumente.

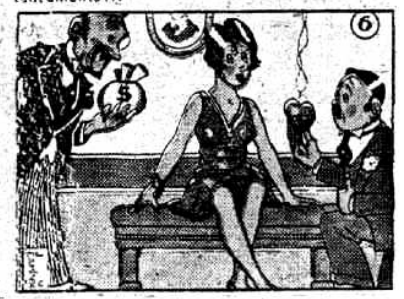

Mezas depois, alegre, faliz, rosada, forte. mal r.tergava para as homenagens que recebia te todos os lados? 


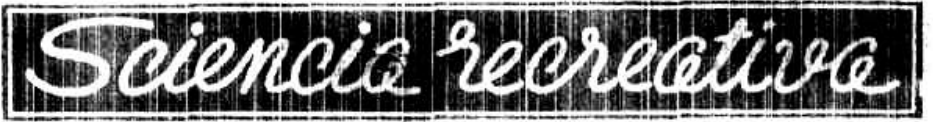

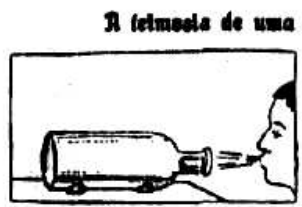

No garzalo do uma garra. ta rnsia, dis. posta horizonfulmenle, ponha-80 uma $\mathrm{m}$ lha de diemo. tro approxima. damento igual a motado da abertura do gargalo; depoís peca-se a qualquer peasou que assopre a rolba aijn do introduzil-a na garrafa Ninguem o conseguirt, pois ai s rollıs so mo. ver serd en sentido contrario no sopro, dando no moto do experimentador em ves de cahir dentro de garraía. A explicacho b simples: o sopre impulsiona a rolhn para dentro, mas lambem comprime o ar que garrafn contim, - prevalecendo aste segundo efteito, ao cossar o primeiro, a rolha es expulas.

\section{Dles wo ates can equitias}

Eis um bel. lo divertimento casoiro. Deso. nho-se um alvo numa porta ou num podaco de madeira, atiram-20 agulbs da distancla de

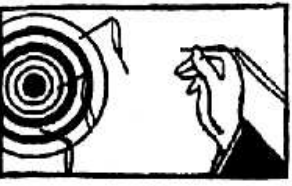

dois metros rnais ou monos. Claro que serh dittiollimo conseguir-se que as agulhas se crsvem ns madeira; portirn, entiando-so- tho uran linha ( $v$. descnho), os raro perier-so um tim. $A$ agulha torna-e zaxis pesada, encontra menor resintencia no ar e lica em posiçäo horivonlad.

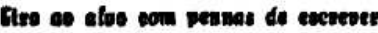

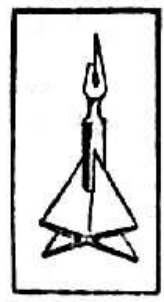

Aqui ests ontro interes. sante divertimento, tiro ao alvo tambern, mas desta vez. com ponnas de escreper. E preferirel que sojam empre. galan pennas velhns, poir $\mathrm{e}$ preciso primeiramento queGrap-be uma das pontas. No outro extremo appliquo-se um pequeno quadrado do papel, dobrando-se ern auns li. uhas diagonaes, tudo confor. me montra o modelo.

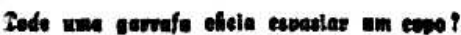

Un copo esvasiar uma gar. rata cheia do que vemos sem. yre; inta o inverso... corno se. re? Eis como faz n magica. Tome-se uma garrafa cheia d'agtan, pondo-se-the uma tampa bem justa. Depois alrares. oo essa tumpa, em lugares differentes, coun dois tubinhon de molal, de vidro ou do bambú. Pondo-so a garrafa do cabeca para baixo $a$ introduzindo-be - extremo do nim dos tubos no conteudo do copo, este so espasiart, passando para interior da garrafa, ern substíluiçso ao liquido que sio

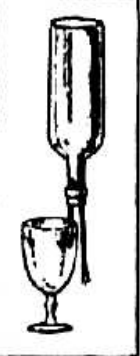

pelo tubo exterior. A garralis cjn seus tubinhos funccions corto um verdsdeiro syphls.

\section{Iode on moser pefo gangelo} de wha semed i

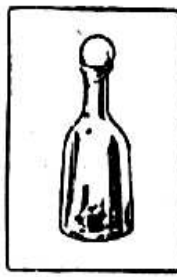

Parce impossivel; entre. tanto, 1 bem simplea. To. me. He um ino cozldo, retire-se- the a casca. Jogue-ec uin papel acoeso dentro de uma garrafa cu. jo gargalo ecja de diametri infarior ao do ovo. Depoir do papel estar quasí tolal. meato queimado, tampo-se a garrifa com o ovo, co. mo si torn uma rolha, de to rijustado. modo a ficat pertoitamen.

o ar contito na garrala, dilatado expulito pola combustao do papel, ao esfriar contrao. sc, o ovo, empurrado peis prossilo almos. pherica, ponetra lealamente pelo gargalo até cahir dentzo da garrala.

\section{inals sopases}

Doatn raz a experiencia o pera provar que muito talo um sopro, memo atrarez de un corpo opuoo. Acoenda-so uma vela o colloquese na aus trento uma garrata. Eata nlo im. pedirs, metrno escondendo a rela, quo do uni sopro so so angoro aquella A rola access de vord licar a uns is conta. da garrafa o asta a uns 15 conts., tambern, da pessos que assopra.

\section{BHOTONICO FODNTOURA \\ - MAIB OOMELITOTOMTIFICANTE




\section{PAGINA DAS

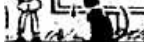

Exercicios de desenho
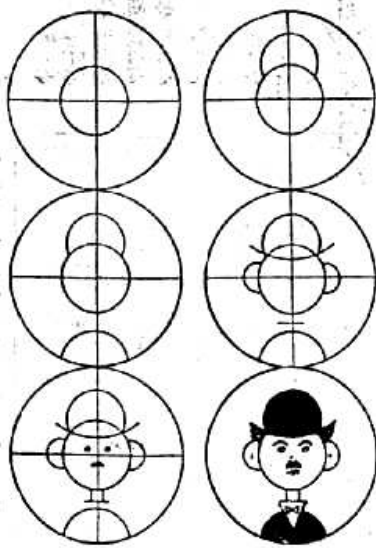

\section{Como se faz o Carlito}

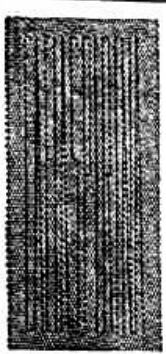

Que é isto? $\mathrm{Um}$ hieroglypho? Não. Olhando bem, inclinando para traz o desenho e fechando um pouco os olhos, lè-se, sem difficuldade, o nome de um famoso producto da Casa Hayer.

\section{Illusões de opliea}

Olhandofixamente estes cuhos, vè̀-se que clles mudam de aspecto edepo. siçāo,tornandose reintrantes os que eram salientes e viceversa.

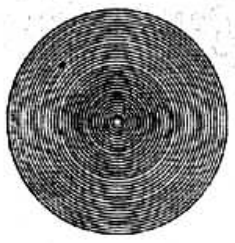

Fixando avista neste disco, vê-se que elle adquire um movirnento circular continuo.

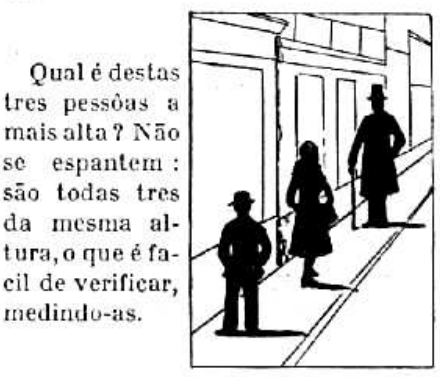

Um gato desenhado com botões
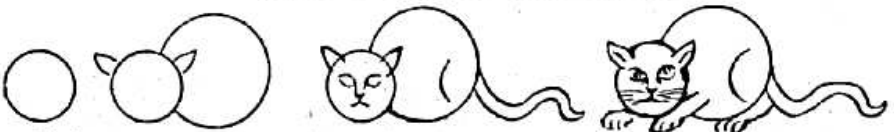

Estes desenhos mostram como é facil desenhar-se um gato. Nada mais preciso que dois botòes de tamanhos differentes, lapis e papel. Colloca-se a botāo maior sobre o papel e desenha-se-the o contorno; faz-se o mesmo com o menor, de modo que os dois circulos se cortem. E agora é só por os traços indicados no desenho. 


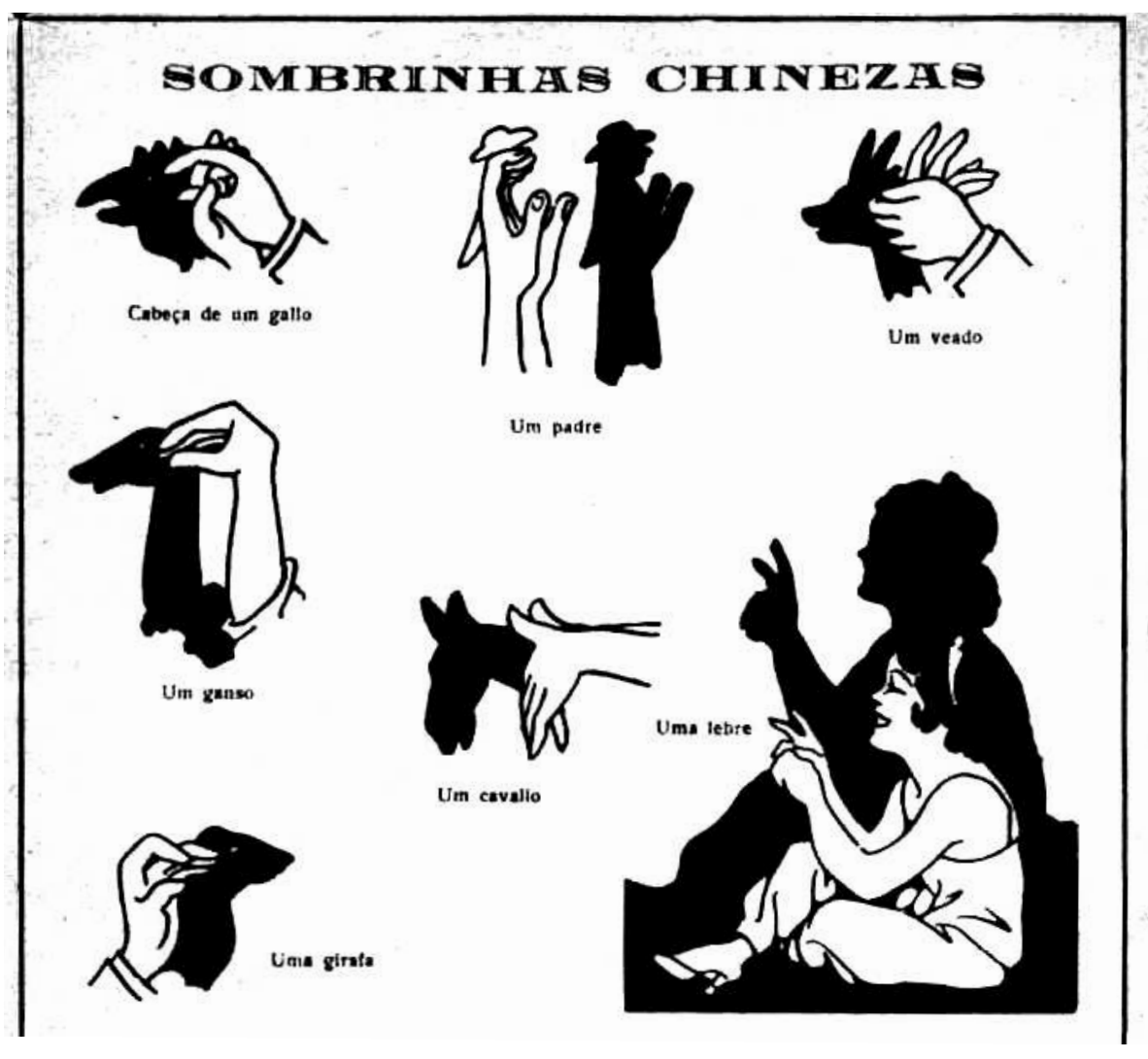




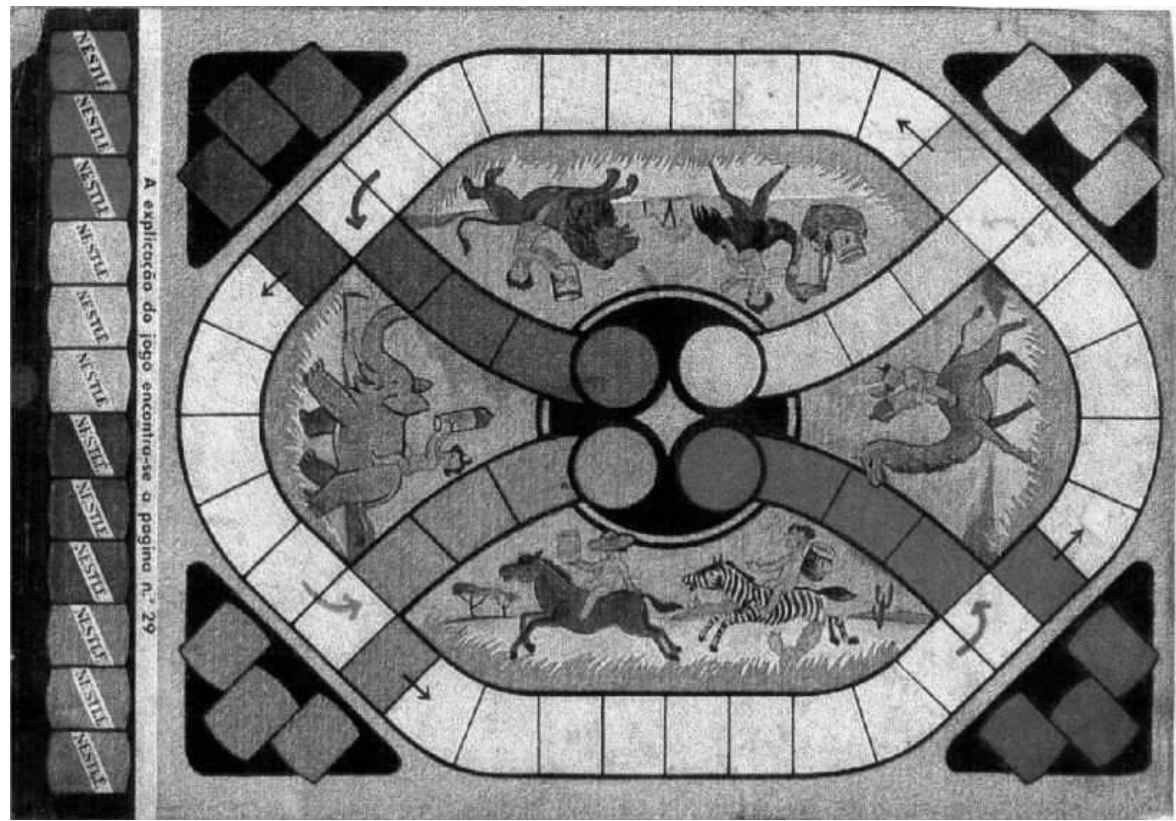

\section{Referências}

ALMEIDA, João A. Guerra de. Amamentação: um híbrido natureza-cultura. Rio de Janeiro: Editora FIOCRUZ, 1999.

BRITES, Olga. Imagens da Infância - São Paulo e Rio de Janeiro, 1930 a 1950. Digitado, 1999. Tese (Doutorado em História), Pontíficia Universidade Católica, São Paulo, 1999. GOUVÊA, M. C. S., PAIXÃO, C. G. Uma nova família para uma nova escola: a propaganda e a produção de sensibilidades em relação à infãncia. In: XAVIER; Maria do Carmo (org.). O legado educacional do Manifesto dos Pioneiros. Rio de Janeiro: Ed. Getúlio Vargas, 2004.

KUHLMANN JR., M. Infância e educação infantil: uma abordagem histórica. 3 ed., Porto Alegre: Mediação, 2004.

MAGALHÃES, Maria das Graças Sandi. A infância nos almanaques de farmácia (1920-1940). Itatiba, 2005. Dissertação (Mestrado em Educação), USF, 2005.

MARQUES, Marília Bernardes. Discursos médicos sobre seres frágeis. Rio de Janeiro: Editora FIOCRUZ, 2000.

MEYER, Marlyse (Org.). Do Almanak aos Almanaques. São Paulo: Ateliê Editorial, 2001. NOVA, Vera Casa. Lições de Almanaque - um estudo semiótico. Belo Horizonte: Editora UFMG, 1996.

PARK, Margareth Brandini. História e Leitura de Almanaques no Brasil. Campinas, SP: Mercado de Letras Editora; Associação de Leitura do Brasil; São Paulo: Fapesp, 1999. 


\section{Notas}

1 Apresentado no VI Congresso Ibero-Americano de História da Educação, Quito, 2005 (Auxílio Viagem FAPESP). Este texto tem como base a pesquisa de mestrado de Magalhães (2005).

2 O conjunto de almanaques (exceto cinco exemplares do acervo da Cia. Nestlé) e grande parte dos livros pesquisados foram recolhidos por Mario Luiz Gomes, que realiza uma pesquisa sobre a história dos almanaques de farmácia. O Colóquio Internacional Os Almanaques Populares: Da Europa à América - Gênero, Circulação e Relações Interculturais, realizado em Campinas e em São Paulo, em 1999, resultou em uma exposição de almanaques brasileiros na Fundação Memorial da América Latina, e na publicação de livro organizado por Marlyse Meyer (2001). Quanto aos laboratórios que mantêm acervo dos almanaques editados, podemos citar o Catarinense, que publica o Almanaque Renascim Sadol, e o Kraemer, que edita o Almanaque Iza (PARK, 1999).

3 No $3^{\circ}$ Congresso Americano da Criança, no Rio de Janeiro, em 1922, aprovou-se a comemoração do dia da criança em 12 de outubro, como referência à chegada de Colombo à América, o que foi adotado no Brasil (KUHLMANN JR., 2004, p. 43-58). A criança como representação do futuro foi tema recorrente em diversas publicações no período estudado (veja-se BRITES, 1999; GOUVÊA, 2004).

4 Conforme consulta ao histórico da empresa, disponível no endereço eletrônico http://www.nestle.com.br, acesso em 12 jun. 2004.

5 A merenda continha uma lata em miniatura do Leite Moça, um pãozinho e um exemplar do Almanaque Nestlé, segundo informações do site da Nestlé Brasil Ltda.: http://www.nestle.com.br, acesso em 12 de junho de 2004.

Recebido: 27/10/2009

Aprovado: 25/11/2009

Contato:

Universidade São Francisco Rua Alexandre Rodrigues Barbosa, 35

CEP 13521-900

Itatiba/SP 
